\title{
Impaired Declarative Memory for Emotional Material Following Bilateral Amygdala Damage in Humans
}

\author{
Ralph Adolphs, ${ }^{1,4}$ Larry Cahill, ${ }^{2}$ Rina Schul, ${ }^{1}$ and Ralf Babinsky ${ }^{3}$ \\ ${ }^{1}$ Department of Neurology \\ Division of Cognitive Neuroscience \\ University of Iowa College of Medicine \\ Iowa City, Iowa 52242 \\ ${ }^{2}$ Center for the Neurobiology of Learning and Memory \\ University of California \\ Irvine, California 92717-3800 \\ ${ }^{3}$ Physiological Psychology \\ University of Bielefeld, \\ D-33501 Bielefeld, Germany
}

\begin{abstract}
Everyday experience suggests that highly emotional events are often the most memorable, an observation supported by psychological and pharmacological studies in humans. Although studies in animals have shown that nondeclarative emotional memory (behaviors associated with emotional situations) may be impaired by lesions of the amygdala, little is known about the neural underpinnings of emotional memory in humans, especially in regard to declarative memory (memory for facts that can be assessed verbally). We investigated the declarative memory of two rare patients with selective bilateral amygdala damage. Both subjects showed impairments in long-term declarative memory for emotionally arousing material. The data support the hypothesis that the human amygdala normally enhances acquisition of declarative knowledge regarding emotionally arousing stimuli.
\end{abstract}

\section{Introduction}

Naturalistic studies of memory for emotional events have suggested that memory for relevant,

${ }^{4}$ Corresponding author. salient information can often be enhanced by emotional arousal (Loftus 1979; Winograd and Neisser 1992). Recent laboratory studies have likewise shown that increased emotional arousal can facilitate the encoding of material into long-term declarative memory in both normal (Bradley et al. 1992) and brain-damaged subjects (Hamann et al. 1997a). Our aim was to test a hypothesis regarding the neuroanatomical structures by which emotion influences memory, using the same, standardized stimuli that have been used in several other studies (Heuer and Reisberg 1990; Burke et al. 1992).

Evidence from both humans and animals indicates that the amygdala may be important in the acquisition of conditioned behavioral and autonomic responses to stimuli that have been paired previously with an intrinsically aversive event (LeDoux et al. 1990; Davis 1992; Bechara et al. 1995; LaBar et al. 1995), although the amygdala does not appear to be essential for the acquisition of all such behaviors (e.g., Tranel and Damasio 1993). The clearest evidence for the amygdala's involvement in modulating memory comes from studies in rats, which have shown that memory is modulated by multiple neurotransmitter systems acting within the amygdala (McGaugh 1989; Cahill and McGaugh 1996; McGaugh et al. 1996). For instance, direct post-training injections into the amygdala of a variety of drugs that modulate GABAergic, noradrenergic, or opiate-mediated neurotransmission influence long-term memory for inhibitory avoidance training (Gallagher et al. 1981;

LEARNING \& MEMORY 4:291-300 @ 1997 by Cold Spring Harbor Laboratory Press ISSN1072-0502/97 \$5.00

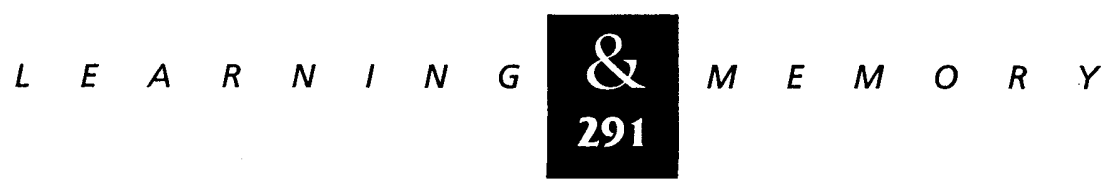


Brioni et al. 1989). Recent data suggest that the amygdala influences memory by modulating encoding and consolidation by other brain structures, such as the hippocampus and basal ganglia (McGaugh 1989; Packard et al. 1994; M.G. Packard and L.A. Teather, unpubl.).

A human subject who had sustained selective bilateral amygdala damage early in life showed a specific inability to judge the intensity of fear in facial expressions (Adolphs et al. 1994, 1995) but no comparable impairment was found in two subjects who had sustained amygdala damage as adults (Hamann et al. 1996), suggesting the hypothesis that the amygdala may be most important in the acquisition (e.g., during development) but not in the retrieval of declarative knowledge about emotions (Adolphs et al. 1996; Hamann et al. 1996; Phelps and Anderson 1997; A. Anderson, K.S. LaBar, and E.A. Phelps, unpubl.). A PET study of normal subjects showed that activation of the right amygdala at the time of encoding was highly correlated with how well emotionally arousing information was subsequently recalled (Cahill et al. 1996). Similarly, recent case studies of patients with bilateral amygdala damage indicated that memory for emotional stimuli was disproportionately impaired (Babinsky et al. 1993; Cahill et al. 1995). A patient with Urbach-Wiethe disease (the sibling of subject B.P. reported in this paper) was impaired on a word-stem completion task for emotional but not for neutral words and likewise showed impaired recognition memory for emotional but not for neutral pictures. Although this evidence from studies in humans remains quite limited, it suggests that the amygdala may play a modulatory role in the acquisition of declarative memories concerning emotionally arousing material.

On the basis of the above findings, we hypothesized that the human amygdala would be required to facilitate encoding of declarative knowledge regarding emotionally arousing stimuli but that it is not required for encoding knowledge of emotionally neutral stimuli. We tested this hypothesis in two rare subjects with selective bilateral amygdala damage. Subjects were presented with a short audiovisual story that contained both neutral and emotionally arousing material, and their declarative memory was assessed at a later time using a standardized multiple-choice questionnaire that asked several questions about the story.

We expected that normal subjects would remember information about emotionally arousing material in the story better than information about more neutral material in the story, as has been found in prior studies (Heuer and Reisberg 1990; Burke et al. 1992; Cahill and McGaugh 1995), but that subjects with amygdala lesions would fail to show this effect. Thus, we expected that subjects with amygdala damage would remember the neutral and the emotionally arousing material in the story about equally well.

A previous study (Cahill et al. 1995) reported some data from the same experiment with one of the patients (B.P.) that we report here and showed that B.P. had impaired memory for the emotional phase of a story; however, data for individual stimuli were not presented in that study. Both the data and the analyses in the present paper are new and provide a much more detailed description of the patient's impairment. These data, together with entirely new findings from a second subject with selective bilateral amygdala damage, provide strong evidence that the human amygdala plays a pivotal role in influencing long-term declarative memory for emotional material.

\section{Experiment 1}

\section{Materials and Methods}

\author{
SUBJECTS
}

We tested subject SM046, who has bilateral damage to the amygdala, six brain-damaged controls without amygdala damage, and seven normal control subjects who overlapped with SM046 in regard to their education, age, and IQ.

SM046 is a 32-year-old woman with a highschool education who suffers from a rare genetic disease, Urbach-Wiethe disease, which has led to bilateral destruction of the amygdala. Her brain damage is restricted to the amygdala, with the exception of minimal damage to left anterior entorhinal cortex (Fig.1A). Her neuroanatomy has been described in detail (Tranel and Hyman 1990; Nahm et al. 1993; Adolphs et al. 1994, 1995). SM046's IQ, visuoperception, and language abilities are all in the normal range (Tranel and Hyman 1990; Adolphs et al. 1995).

SM046 and the six brain-damaged controls had all been selected from the Patient Registry of the Division of Behavioral Neurology and Cognitive Neuroscience at the University of Iowa and had

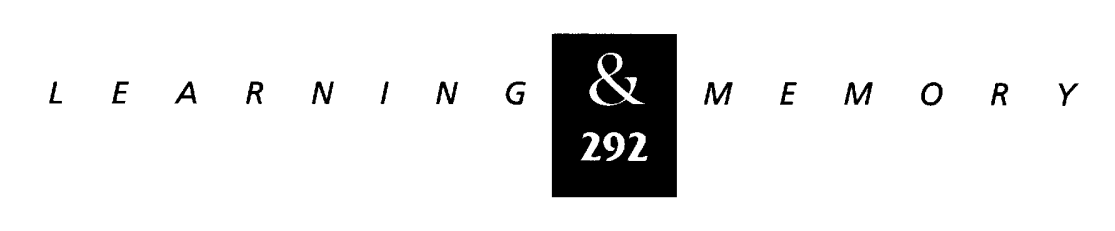


A

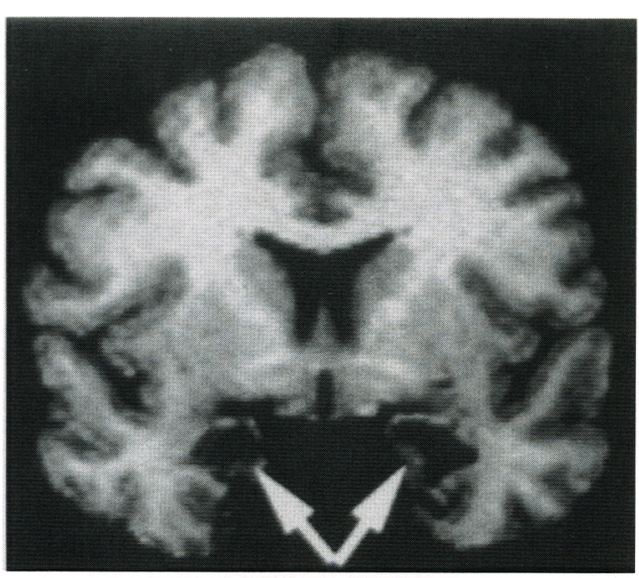

B

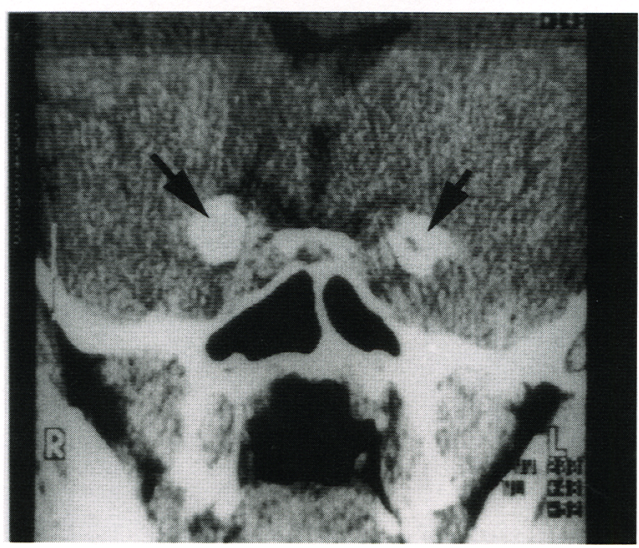

Figure 1: Images of the brains of SM046 and B.P. at the level of the amygdala. (A) T1-weighted magnetic resonance $(M R)$ image of SM046's brain showing bilateral amygdala lesions (arrows, dark regions on the MR scan). (B) CT scan of B.P.'s brain showing bilateral amygdala lesions (arrows, white radio-opaque regions on CT scan). The amygdala pathology in both SM046 and B.P. is due to calcification of tissue.

been fully characterized neuroanatomically and neuropsychologically according to the standard protocols of the Benton Neuropsychology Laboratory (Tranel 1996) and the Laboratory of Neuroimaging and Human Neuroanatomy (Damasio and Damasio 1989; Damasio and Frank 1992). Neuroanatomical description for these subjects had been obtained from three-dimensional reconstructions of their brains (Damasio and Frank 1992; Frank et al. 1997). Brain-damaged control subjects (age $=54 \pm 16$ ) included subjects with damage to occipital, frontal, and parietal cortices. Two of the subjects were aphasic, and three had bilateral lesions. None had damage to amygdala, hippocampus, or adjacent structures, and none were amnesic.
The seven normal controls included individuals whose age, education, and IQ were matched to that of SM046 (age: SM0 46 $=32$, control mean $=36 \pm 8.5 ; \quad$ IQ: $\mathrm{SM} 046=86, \quad$ control mean $=98 \pm 10 ;$ education: SM046 $=12$ years, control mean $=12$ years).

\section{EXPERIMENTAL TASK}

To study the modulation of declarative memory by emotion, we used a task that has been administered to normal human subjects in several studies, with reliable findings (Heuer and Reisberg 1990; Burke et al. 1992; Reisberg and Heuer 1992; Cahill and McGaugh 1995). The task consists of a set of 12 slides that are shown in sequence, accompanied by a narrative. Together, the slides and narrative tell a story about a boy and his mother who visit the father at the hospital. The story can be divided into three phases: phase 1 (the first four slides) consists of material that is normally judged not to be very emotional (the boy and mother are on their way to the hospital), phase 2 (the middle four slides) contains emotionally arousing material (scenes of surgery at the hospital), and phase 3 (the last four slides) consists again of relatively nonemotional material (the mother leaves the hospital to make a phone call and goes home). The verbatim narrative that accompanied the slides is given in the Appendix.

Subjects were told to pay close attention to the stimuli, because they would subsequently be asked about their emotional reaction; subjects were not told and did not expect that this was a test of memory. Slides were shown projected on a wall in a darkened room (size of images $=1 \times 1.5 \mathrm{~m}$ ), and the narrative was spoken by the experimenter (R.A.). Stimuli were shown for $20 \mathrm{sec}$, with no interstimulus interval. Immediately after presentation of the stimuli, subjects were asked to rate their personal emotional reaction to the story (on a scale of $0-10$ ).

Memory for the stimuli was assessed $24 \mathrm{hr}$ later, using an established multiple-choice questionnaire (Heuer and Reisberg 1990). The questionnaire asked 9-10 questions about each slide.

\section{Results}

Two rare subjects with focal bilateral amygdala damage were tested in two separate experiments,

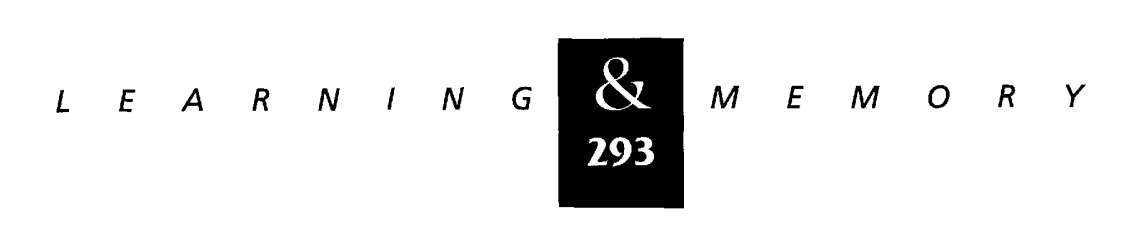


which used similar stimuli and procedures. Experiment 1 concerns subject SM046 and controls matched to her; experiment 2 concerns subject B.P. and controls matched to him. We wanted to know what impairments the two subjects might share in common across the two experiments. To permit a direct comparison, corresponding data from each of the two experiments are shown as adjacent parts in all figures.

In experiment 1 we showed subject SM046, six brain-damaged controls, and seven normal controls of similar age, education, and IQ 12 slides accompanied by a narrative. Immediately after having seen the stimuli, all subjects rated the story as emotionally arousing. Ratings of emotional arousal given by SM046 did not differ appreciably from the ratings given by controls (Fig. $2 \mathrm{~A}$ ).

Subjects were given a multiple-choice questionnaire about the stimuli $24 \mathrm{hr}$ later. Performances on this questionnaire are shown in Figure 3A. The normal controls' memory for declarative knowledge regarding the stimuli they had seen earlier was very similar to that of normal subjects in prior studies (Cahill and McGaugh 1995; experiment 1), showing a characteristic profile (Fig. 3A, top panel). Most notably, there was a highly reproducible peak in performance for slide 7 . For all normal subjects and for all brain-damaged controls, material regarding slide 7 was remembered best of any of the 12 slides. This performance was expected, because slide 7 , a picture of surgically repaired legs of a car-crash victim, is one of the most emotionally arousing stimuli.

Although SM046 showed a profile of declarative memory on this task that was similar to that of the controls for most stimuli, her performance featured a notable discrepancy: SM046, unlike any other subject, did not remember well information regarding slide 7 . Whereas this slide is remem- bered best by all other subjects, SM046 remembered it no better than other, emotionally nonarousing slides (Fig. 3A, bottom panel). These data are what would be predicted from the hypothesis that the amygdala is necessary to facilitate memory for emotionally arousing material. The specificity of the effect argues strongly against a general memory impairment in SM046.

To directly compare SM046's performance with that of the controls, we calculated the difference between subjects' scores and the mean score obtained by normal controls. This analysis is shown for SM046 and for the six brain-damaged controls in Figure 4A. SM046 differed markedly from normals only on slide 7 (by 7 S.D.s), and this difference was larger than the difference obtained by any of the six brain-damaged controls. She thus showed a specific impairment in her ability to remember information about the emotionally most arousing slide.

\section{Experiment 2}

\section{Materials and Methods}

SUBJECTS

We tested subject B.P., who, like subject SM046 above, suffers from Urbach-Wiethe disease and has bilateral amygdala damage (Fig.1B), and six normal controls similar to B.P. in age and education (age: $B . P .=37$, control mean $=35 \pm 1.5$; education: B.P. $=10$, control mean $=10.5 \pm 0.7$ years) . B.P.'s IQ, language, and perceptual abilities are all in the normal range. Details regarding B.P.'s neuropsychological background and lesions have been
A

Figure 2: Ratings of emotionality. Subjects were asked to rate their emotional reaction to the story, immediately after its presentation, on a scale of 0 (not emotional at all) to 10 (maximally emotional). SMO46 and B.P. endorsed normal ratings. (A) Ratings from SM046, six brain-damaged controls, and seven normal controls demographically similar to SM046. (B) Ratings from B.P. and six normal, native German-speaking controls (data from Cahill et al. 1995).
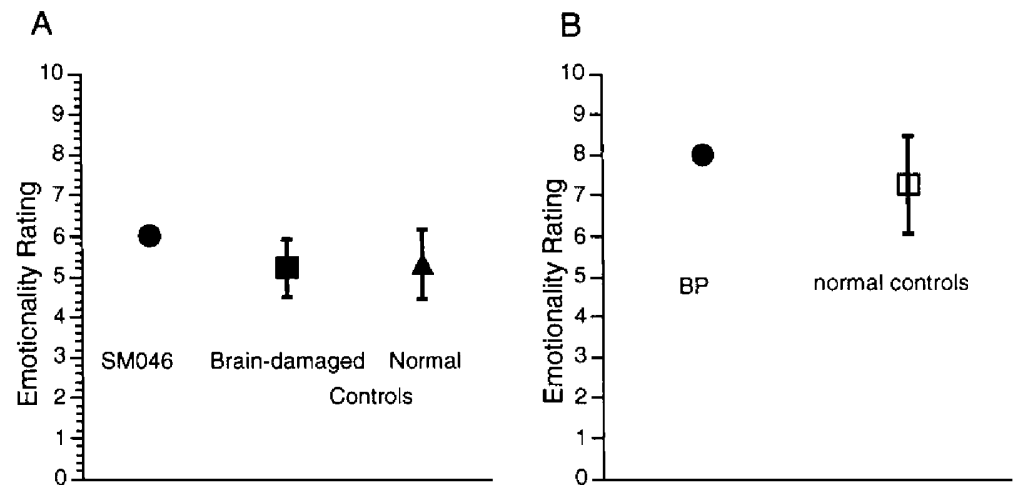

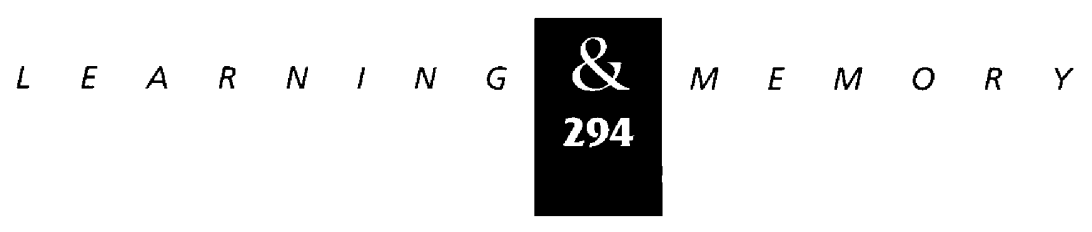




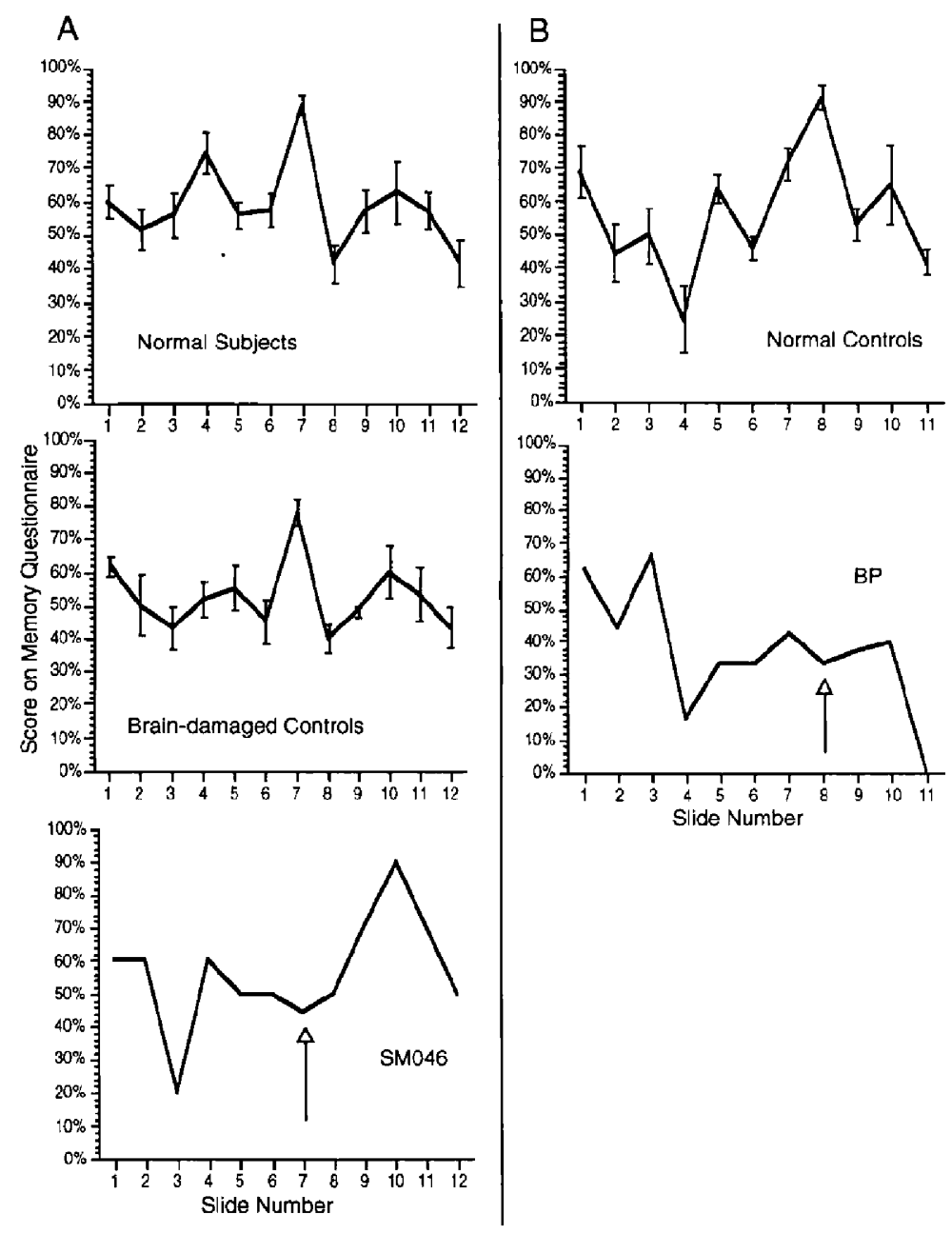

Figure 3: Declarative memory for emotional stimuli is impaired in subjects with bilateral amygdala damage. SM046 and B.P. did not show the normal enhancement of memory for emotionally arousing material (arrows). (A) Memory scores from experiment 1 for (top) seven normal controls similar to SM046 in age, education, and IQ (means \pm S.E.M.; (middle) six brain-damaged controls; (bottom) subject SM046. There were 9-10 questions per slide; chance is at $25 \%$. (B) Memory scores from experiment 2 for (top) six normal, native German-speaking controls similar to B.P. in age and education (means \pm S.E.M.); (bottom) B.P. There were $6-10$ questions per slide, and chance is at $25 \%$. published previously (Markowitsch et al. 1994; Cahill et al. 1995).

\section{EXPERIMENTAL TASK}

A set of 11 slides accompanied by narrative was presented to subjects. The story was essentially that used in previous investigations (Cahill et al. 1994; Cahill and McGaugh 1995, expt. 2) and was highly similar to the story used in experiment 1 (cf. Appendix). Most of the slides used in experiment 2 were identical to those used in experiment 1. Minor changes were made to the story version used previously by Cahill et al. (1994) to enhance story continuity. Also, the story was translated into German, because B.P. and controls were native German speakers. The stimulus that was most emo- tional (showing surgically reattached legs) was identical in both experiments 1 and 2. For experiment 2 , phase 1 consisted of the first four, emotionally neutral, stimuli; phase 2 consisted of the next four, emotionally arousing, stimuli; and phase 3 consisted of the last three, relatively neutral stimuli.

Subjects were shown the slides and read the narrative by the experimenter (R.B.), using a protocol identical to that described for experiment 1 , above. After presentation of the stimuli, subjects were asked to rate their personal emotional reaction to the story (on a scale of 0-10). Declarative memory was assessed 1 week later, using a multiple-choice questionnaire that has been used successfully in previous studies (Cahill et al. 1994; Cahill and McGaugh 1995). This questionnaire differed somewhat from the one used in experiment

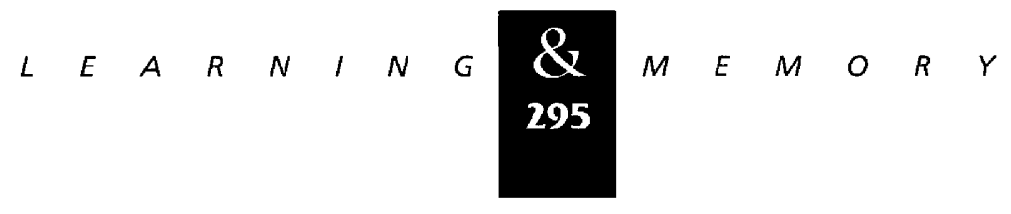



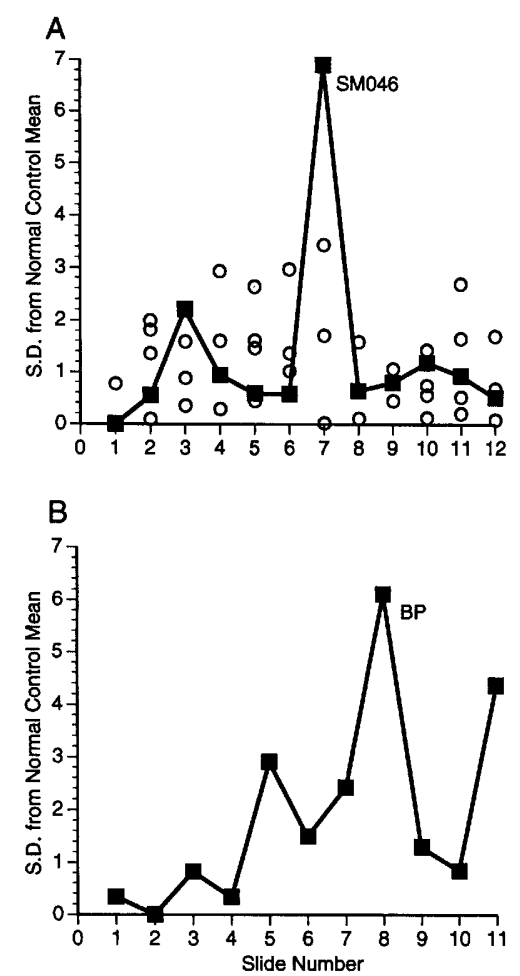

Figure 4: Subjects with amygdala damage differ most from controls in declarative memory for highly emotional material. Both SM046 (top) and B.P. (bottom) ( $\mathbf{\square}$, solid lines) differed most from controls on a highly emotional slide showing the surgically reattached legs of a car-crash victim. They differed by $>6$ s.D.s from the control mean, an impairment not shown by any of the braindamaged control subjects $(O)$.

1 and had been translated into German. The questionnaire asked 6-10 questions about each slide.

\section{Results}

In experiment 2 , we showed subject B.P. and six normal controls matched on age and education a story very similar to that used in experiment 1 . This story had 11 slides, and memory was assessed 1 week later using a somewhat different questionnaire from the one used in experiment 1 (see Materials and Methods for details). Immediately after having seen the stimuli, B.P. and the six normal controls also endorsed the story as highly emotional (Fig. 2B), and B.P. did not differ from the controls on this measure.

The normal controls in experiment 2 remembered best material regarding the slide showing the surgically repaired legs of the car-crash victim (slide 8 in experiment 2, identical to slide 7 in experiment 1), data very similar to those obtained with the somewhat different narrative of experiment 1. B.P. did not show the normal enhancement of memory for emotionally arousing stimuli and gave a performance for slide 8 that was no better than that for the prior, neutral stimuli (Fig. 3B). The results obtained from B.P. using the stimuli of experiment 2 are thus similar to those obtained from SM046 using the stimuli from experiment 1 (Fig. 3A,B). Unlike control subjects and subject SM046, B.P. also gave an abnormally poor performance on the very last stimulus (slide 11 in experiment 2). We consider B.P.'s performance on this particular slide an aberration, as it was below the level expected by chance (25\%).

We also analyzed B.P.'s data in terms of his difference from the control mean (Fig. 4B). Like SM046, B.P. differed most from controls on the emotionally most arousing slide (slide 8 ). Neither of the two patients with amygdala damage showed the normal pattern of best memory for the most emotionally arousing material in the story. The analysis for B.P. shows impaired memory for several slides in the middle portion of the story beginning with slide 5 , the slide at which the emotional story elements were first introduced (see Appendix, experiment 2).

\section{General Discussion}

Experiments 1 and 2 yielded similar findings. Taken together, the data strongly support the following conclusions: First, control subjects gave a highly reliable performance profile on the emotional memory tasks we used. We found that, in normal subjects as well as in the six brain-damaged subjects of experiment 1 , declarative long-term memory for emotionally arousing stimuli was better than memory for neutral stimuli, consistent with several reports published previously (Heuer and Reisberg 1990; Burke et al. 1992; Reisberg and Heuer 1992; Cahill et al. 1994, 1995, 1996; Cahill and McGaugh 1995; Hamann et al. 1997a). These findings are also consistent with the accompanying study by Hamann et al. (this issue), which reported normal facilitation of declarative emotional memory in amnesic and normal subjects. Second, because all subjects reported that they found the stimuli emotionally arousing during initial exposure, the most parsimonious explanation of the enhanced memory for emotional stimuli in control

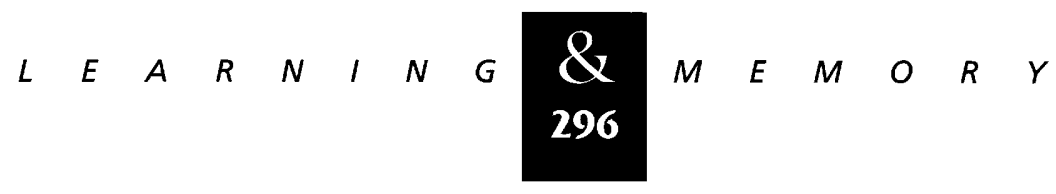


subjects is that emotional arousal enhanced the acquisition of declarative knowledge, data again consonant with previous findings (Bradley et al. 1992; Cahill et al. 1994). Third, bilateral damage to the amygdala abolished the above effect. Specifically, both subjects with amygdala damage failed to show enhanced memory for emotionally arousing material. Fourth, given that we replicated the findings in two different subjects with amygdala lesions, using two somewhat different sets of stimuli, alternative explanations of the data are less likely. Furthermore, we controlled for several possibly confounding factors in choosing demographically similar normal control subjects, and we controlled for an effect of brain damage per se by testing brain-damaged controls in experiment 1 . It is thus unlikely that the findings can be explained on the basis of age, IQ, education, or nonspecific brain damage.

\section{AMYGDALA DAMAGE IMPAIRS MEMORY FOR EMOTIONALLY CHARGED STIMULI}

Although the data from both subjects with amygdala damage, SM046 and B.P., support the hypothesis that the human amygdala is required to enhance memory for emotionally arousing stimuli, the two subjects did not yield identical data. SM046 showed a particularly specific effect, differing from controls on the slide that is most emotionally arousing and that is normally remembered best. Although her performance also differed from that of normal controls on some of the other slides (notably $\# 3$ and $\# 10$ ), all these differences were well within the range also shown by brain-damaged controls who did not have amygdala damage. Unlike any brain-damaged control, SM046 differed from normal performance on slide 7 by $>7$ S.D.s, a highly abnormal performance.

B.P. also showed impaired memory for this same emotionally arousing slide, as well as for other emotional slides in the middle phase of the story. However, unlike SM046, B.P. also showed impaired memory for the last several slides, which were relatively neutral (phase 3 ), and obtained a score of $0 \%$ on the very last slide (slide 11 in experiment 2). As we pointed out in Results, we believe B.P.'s performance on slide 11 was an aberration, as it was well below the performance expected by chance. His performance on slides 9 and 10 , although low, was within a standard deviation of the control mean, as were his performances for all stimuli in phase 1 (slides $1-4$ ). His score on slide 8 deviated the most from the control scores ( $>6$ S.D.s lower than the mean). Taken together, SM046 and B.P. share a pattern in common: The slide on which their memory score deviated the most from controls (slide 7 in experiment 1, identical to slide 8 in experiment 2) was also the slide that normal subjects remembered best. This slide, showing the surgically reattached legs of a car-crash victim, is normally found to be the most emotional of the stimuli. The specificity of the finding and the striking parallel between the pattern of results obtained from two rare subjects with selective bilateral amygdala lesions strongly support the view that the amygdala plays a key role in the enhancement of long-term declarative memory when the subject matter is highly emotional (Babinsky et al. 1993; Cahill et al. 1995, 1996; Phelps and Anderson 1997).

\section{AMYGDALA MODULATION OF MEMORY}

Our findings are consonant with studies in animals suggesting that the amygdala does not directly mediate encoding of declarative knowledge (ZolaMorgan et al. 1989; Murray 1992) but rather that it modulates acquisition and consolidation of such knowledge mediated by other structures, such as hippocampus and basal ganglia. For example, injections of D-amphetamine into the amygdala immediately after training enhance performance on both spatial and cued water-maze tasks (Packard et al. 1994). Reversible pharmacological lesions with lidocaine suggest that the amygdala-mediated enhancement depends on the hippocampus (for the spatial task) or caudate nucleus (for the cued task). Lidocaine injections into either the hippocampus or caudate block the enhancement owing to D-amphetamine amygdala injections on the respective task but leave the amygdala's enhancement of the other task unaffected (M.G. Packard and L.A. Teather, unpubl.).

\section{THE AMYGDALA'S ROLE IN EMOTIONALLY INFLUENCED MEMORY MAY BE INDEPENDENT OF EMOTIONAL EXPERIENCE}

The precise stage at which processing is impaired by amygdala damage is unclear. Did our amygdala subjects simply not feel emotionally aroused by the stimuli, or did they perhaps not

$$
\ldots \ldots, \text { 图 }
$$


even recognize the stimuli as emotional? The ratings the subjects gave, as well as extensive conversations with subject SM046, argue against this possibility, although it remains possible that the subjects did not experience the emotional stimuli entirely normally. After completion of the experiment, SM046 explained that she had found the slide with the surgically repaired legs quite emotional and unpleasant, a comment she also made spontaneously when she first saw the slides. She has made similarly appropriate comments in regard to her experience of a large number of emotionally charged stimuli we have shown her, as well as in regard to emotional events from her own life. These findings are consonant with those from another study, in which two patients with complete bilateral amygdala damage rated the emotional arousal of a large number of stimuli normally (Hamann et al. 1997a). Support comes also from a recent $P E T$ study, in which activation of the amygdala correlated with memory for emotionally arousing stimuli but not with subjective emotional arousal per se (Cahill et al. 1996). It may thus be that the experience of emotional events does not depend essentially on the amygdala. The amygdala's function in humans appears to be rather more subtle, serving to mediate between the evaluation and experience of emotional events, on the one hand, and their acquisition and consolidation into long-term memory, on the other.

\section{Acknowledgments}

We thank Antonio Damasio, James McGaugh, Hans Markowitsch, and Daniel Tranel for helpful comments on the manuscript and Daniel Reisberg and Friderike Heuer for providing the stimuli. This work was supported in part by National Institute of Neurological Disorders and Stroke grant P01 NS 19632 to A.R. Damasio and a Fulbright scholarship to R.S.

The publication costs of this article were defrayed in part by payment of page charges. This article must therefore be hereby marked "advertisement" in accordance with 18 USC section 1734 solely to indicate this fact.

\section{References}

Adolphs, R., D. Tranel, H. Damasio, and A. Damasio. 1994. Impaired recognition of emotion in facial expressions following bilateral damage to the human amygdala. Nature 372: 669-672.

Adolphs, R., D. Tranel, H. Damasio, and A.R. Damasio. 1995. Fear and the human amygdala. J. Neurosci. 15: 5879-5892.
Adolphs, R., H. Damasio, D. Tranel, and A.R. Damasio. 1996. Cortical systems for the recognition of emotion in facial expressions. J. Neurosci. 16: 7678-7687.

Babinsky, R., P. Calabrese, H.F. Durwen, H.J. Markowitsch, D. Brechtelsbauer, L. Heuser, and W. Gehlen. 1993. The possible contribution of the amygdala to memory. Behav. Neurol. 6: 167-170.

Bechara, A., D. Tranel, H. Damasio, R. Adolphs, C. Rockland, and A.R. Damasio. 1995. Double dissociation of conditioning and declarative knowledge relative to the amygdala and hippocampus in humans. Science 269: $1115-1118$.

Bradley, M.M., M.K. Greenwald, M.C. Petry, and P.J. Lang. 1992. Remembering pictures: Pleasure and arousal in memory. J. Exp. Psychol. Learn. Mem. \& Cog. 18: 379-390.

Brioni, J.D., A.H. Nagahara, and J.L. McGaugh. 1989. Involvement of the amygdala GABAergic system in the modulation of memory storage. Brain Res. 487: 105-112.

Burke, A., F. Heuer, and D. Reisberg. 1992. Remembering emotional events. Mem. Cognit. 20: 277-290.

Cahill, L. and J.L. McGaugh. 1995. A novel demonstration of enhanced memory associated with emotional arousal. Consciousness and Cognit. 4: 410-421.

1996. Modulation of memory storage. Curr. Opin. Neurobiol. 6: 237-242.

Cahill, L., B. Prins, M. Weber, and J.L. McGaugh. 1994. Beta-adrenergic activation and memory for emotional events. Nature 371: 702-704.

Cahill, L., R. Babinsky, H.J. Markowitsch, and J.L. McGaugh. 1995. The amygdala and emotional memory. Nature 377: 295-296.

Cahill, L., R.J. Haier, J. Fallon, M.T. Alkire, C. Tang, D. Keator, J. Wu, and J.L. McGaugh. 1996. Amygdala activity at encoding correlated with long-term, free recall of emotional information. Proc. Natl. Acad. Sci. 93: 8016-8021.

Damasio, H. and A.R. Damasio. 1989. Lesion analysis in neuropsychology. Oxford University Press, New York, NY.

Damasio, H. and R. Frank. 1992. Three-dimensional in vivo mapping of brain lesions in humans. Arch. Neurol. 49: $137-143$.

Davis, M. 1992. The role of the amygdala in conditioned fear. In The amygdala: Neurobiological aspects of emotion, memory, and mental dysfunction (ed. J.P. Aggleton). Wiley-Liss, New York, NY.

Frank, R.J., H. Damasio, and T.J. Grabowski. 1997. Brainvox: An interactive, multi-modal visualization and analysis system for neuroanatomical imaging. Neurolmage 5: 13-30. 
Gallagher, M., B.S. Kapp, J.P. Pascoe, and P.R. Rapp. 1981. A neuropharmacology of amygdaloid systems which contribute to learning and memory. In The amygdaloid complex (ed. Y. Ben-Ari). Elsevier, Amsterdam, Netherlands.

Hamann, S.B., L. Stefanacci, L.R. Squire, R. Adolphs, D. Tranel, H. Damasio, and A.R. Damasio. 1996. Recognizing facial emotion. Nature 379: 497.

Hamann, S.B., L. Cahill, and L.R. Squire. 1997a. Emotional perception and memory in amnesia. Neuropsychology 11: 104-113.

Hamann, S.B., L. Cahill, J. McGaugh, and L.R. Squire. 1997b. Intact enhancement of declarative memory for emotional material in amnesia. Learn. \& Mem. (this issue).

Heuer, F. and D. Reisberg. 1990. Vivid memories of emotional events: The accuracy of remembered minutiae. Mem. Cognit. 18: 496-506.

LaBar, K.S., J.E. LeDoux, D.D. Spencer, and E.A. Phelps. 1995. Impaired fear conditioning following unilateral temporal lobectomy in humans. J. Neurosci. 15: 6846-6855.

LeDoux, J.E., P. Cicchetti, A. Xagoraris, and L.M. Romanski. 1990. The lateral amygdaloid nucleus: sensory interface of the amygdala in fear conditioning. J. Neurosci. 10: 1062-1069.

Loftus, E.F. 1979. Eyewitness testimony. Harvard University Press, Cambridge, MA.

Markowitsch, H.J., P. Calabrese, M. Wuerker, H.F. Durwen, J. Kessler, R. Babinsky, D. Brechtelsbauer, L. Heuser, and W. Gehlen. 1994. The amygdala's contribution to memory-a study on two patients with Urbach-Wiethe disease. NeuroReport 5: 1349-1352.

McGaugh, J.L. 1989. Involvement of hormonal and neuromodulatory systems in the regulation of memory storage. Annu. Rev. Neurosci. 12: 255-287.

McGaugh, J.L., L. Cahill, and B. Roozendaal. 1996. Involvement of the amygdala in memory storage: Interaction with other brain systems. Proc. Natl. Acad. Sci. 93: 13508-13514.

Murray, E.A. 1992. Medial temporal lobe structures contributing to recognition memory: The amygdaloid complex versus the rhinal cortex. In The amygdala: Neurobiological aspects of emotion, memory, and mental dysfunction (ed. J.P. Aggleton). Wiley-Liss, New York, NY.

Nahm, F.K.D., D. Tranel, H. Damasio, and A.R. Damasio. 1993. Cross-modal associations and the human amygdala. Neuropsychologia 31: 727-744.

Packard, M.G., L. Cahill, and J.L. McGaugh. 1994. Amygdala modulation of hippocampal-dependent and caudate nucleus-dependent memory processes. Proc. Natl. Acad. Sci. 91: 8477-8481.
Phelps, E.A. and A.K. Anderson. 1997. What does the amygdala do? Curr. Biol. 7: R311-R314.

Reisberg, D. and F. Heuer. 1992. Remembering the details of emotional events. In Affect and accuracy in recall: Studies of "flashbulb" memories (ed. E. Winograd and U. Neisser). Harvard University Press, Cambridge, MA.

Tranel, D. 1996. The lowa-Benton school of neuropsychological assessment. In Neuropsychological assessment of neuropsychiatric disorders (ed. I. Grant and K.M. Adams). Oxford University Press, New York, NY.

Tranel, D. and B.T. Hyman. 1990. Neuropsychological correlates of bilateral amygdala damage. Arch. Neurol. 47: 349-355.

Tranel, D. and A.R. Damasio. 1993. The covert learning of affective valence does not require structures in hippocampal system or amygdala. J. Cognit. Neurosci. 5: 79-88.

Winograd, E. and U. Neisser. 1992. Affect and accuracy in recall: Studies of "flashbulb" memories. Harvard University Press, Cambridge, MA.

Zola-Morgan, S., L.R. Squire, and D.G. Amaral. 1989. Lesions of the amygdala that spare adjacent cortical regions do not impair memory or exacerbate the impairment following lesions of the hippocampal formation. J. Neurosci. 9: $1922-1936$.

Received June 30, 1997; accepted in revised form September 23, 1997.

\section{APPENDIX: NARRATIVE TO ACCOMPANY SLIDES}

\section{EXPERIMENT 1 (VERBATIM TEXT):}

1. Mother and son are leaving home in the morning.

2. They make sure that crossing Park Road is safe.

3. She is taking him to visit his dad at work.

4. Father is a chief surgeon at a nearby hospital.

5. Earlier in the day there had been a terrible accident.

6. The surgical team has been fighting to save the victims.

7. Father was able to restore the severed limbs.

8. He is pleased that his son watched the surgery.

9. Mother leaves the hospital, upset by what she saw.

10. Heading to call work, she passes a police station.

11. Mother asks her boss to get the day off.

12. She tries to hail a cab home at the number three bus stop.

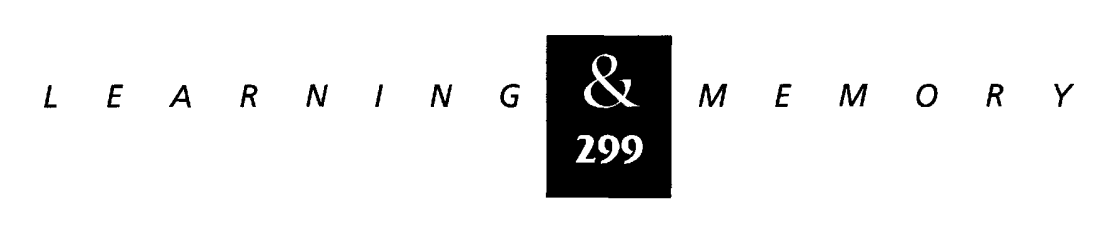


Adolphs et al.

EXPERIMENT 2 (TEXT TRANSLATED FROM

GERMAN):

1. A mother and her son are leaving home in the morning.

2. She is taking him to visit his father's workplace.

3. The father is the chief laboratory technician at a nearby hospital.

4. They check before crossing a busy road.

5. While crossing the road, the boy is struck by a runaway car, which critically injures him.

6. At the hospital, the staff prepare the emergency room, to which the boy is rushed.

7. All morning long, a surgical team struggled to save the boy's life.

8. Specialized surgeons were able to successfully reattach the boy's severed feet.

9. After the surgery, while the father stayed with the boy, the mother left to phone her other child's preschool.

10. Feeling distraught, she phones the preschool to tell them she will soon pick up her child.

11. Heading to pick up her child, she hails a taxi at the number nine bus stop. 


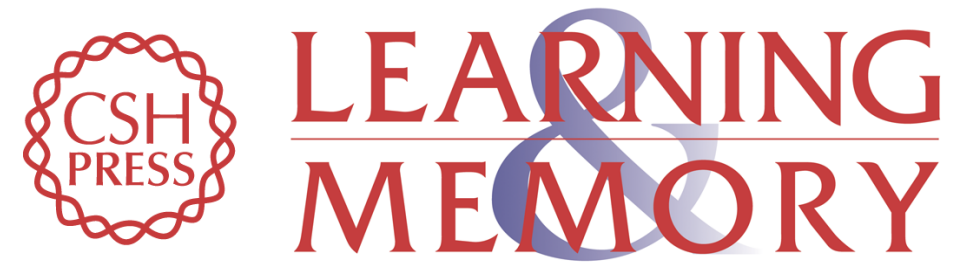

\section{Impaired declarative memory for emotional material following bilateral amygdala damage in humans.}

R Adolphs, L Cahill, R Schul, et al.

Learn. Mem. 1997, 4:

Access the most recent version at doi:10.1101//m.4.3.291

References This article cites 29 articles, 9 of which can be accessed free at: http://learnmem.cshlp.org/content/4/3/291.full.html\#ref-list-1

License

Email Alerting Receive free email alerts when new articles cite this article - sign up in the box at the Service top right corner of the article or click here. 